\title{
Chronic Benign Congenital Myopathy: Fingerprint Body Type
}

\author{
A. S. GORDON, N. B. REWCASTLE, J. G. HUMPHREY \& B. M. STEWART
}

SUMMARY The term "benign congenital myopathy" describes a group of muscle disorders characterized by proximal or diffuse muscle weakness, a relatively non-progressive course, normal serum muscle enzyme assays and the presence of a distinctive morphological feature. We report here a 55 year old woman, with fingerprint body myopathy who exhibits all of the above features. She has been affected from birth, able to walk since the age of 12, and has not deteriorated in the past thirty years. Muscle biopsy reveals fatty infiltration, numerous small fibers undergoing structural change, good dif-

RESUMÉ: Le terme de myopathie congénitale bénigne désigne un ensemble de troubles musculaires, caractérisés par une faiblesse musculaire générale ou locale, un développement relativement lent, des taux sériques d'enzymes musculaires normaux, ainsi que par la présence d'un caractère morphologique distinct. Nous mentionnons ici le cas d'une dame de 55 ans, souffrant d'une myopathie de l'empreinte digitale, présentant tous les caractères décrits cidessus. Cette myopathie congénitale ne lui a pas permis de marcher avant l'âge de 12 ans, et son état est resté stationnaire depuis 30 ans. Une biopsie musculaire révéla la présence d'une infiltration graisseuse, ainsi que de nombreuses petites fibres en cours d'évolu- ferentiation into type I and II fibers, and excessive intracellular lipid and lipochrome. Only on electron microscopic study is the distinctive feature of numerous subsarcolemmal round to ovoid fingerprint bodies observed. Many fibers also contain large collections of tubular aggregates, filamentous bodies, and autophagic vacuoles.

The fingerprint bodies are similar to the ones described by A. Engel in a 5 year old girl. Thus, a rare opportunity is provided to study an individual who has had this disease for over fifty years.

tion structurale, une bonne différenciation des fibres de type 1 et de type 2, et un excés intra-cellulaire de lipide et de lipochrome. Ce n'est qu'à l'examen au microscope-électron que l'on décela, sur l'empreinte digitale, la présence de nombreux corps ronds sous-sarcolemnes caractéristiques. On remarqua également que beaucoup de fibres contenaient un grand nombre d'agrégats tubulaires, de corps filamenteux et de vacules autophages.

Le dessin de cette empreinte digitale est semblable à celui rencontré par A. Engel chez une fillette de 5 ans; cette patiente apporte donc l'occasion rare d'examiner une personne souffrant de cette maladie depuis plus de cinquante ans.
From the Division of Neuropathology, Department of Pathology, University of Toronto and St. Michael's Hospital, Toronto.

Supported by the Muscular Dystrophy Association of Canada

Presented at the joint meeting of the Canadian Congress of Neurological Sciences and the American Neurological Association, in Montreal, June 10-13, 1973.

Reprint address - Dr. N. B. Rewcastle, Dept. of Pathology, University of Toronto, 100 College St. Toronto 2, Canada.
The term "benign congenital myopathy" refers to a group of muscle diseases characterized by proximal or diffuse muscle weakness, a relatively non-progressive course, normal serum muscle enzymes and the presence of a distinguishing morphological feature (Engel et al, 1972). Included among these conditions are nemaline (rod) myopathy, (Shy et al, 1963), central core disease, (Shy and Magee, 1956), multicore disease (Engel et al, 1971), myotubular myopathy (Spiro et al, 1966), congenital pleoconial and megaconial myopathy (Shy et al, 1966), type I fiber hypotrophy and central nuclei, (Engel et al, 1968), centronuclear myopathy (Sher et al, 1967), familial myopathy with probable lysis of myofibrils in type I fibers (Cancilla et al, 1971), reducing body myopathy (Brooke and Neville, 1971), sarcotubular myopathy (Jerusalem et al, 1973), and fingerprint body myopathy (Engel et al, 1972).

To date, only one instance of a fingerprint myopathy has been described and that was in a 5 year old girl (Engel et al, 1972), We wish to report a female who has had a clinically benign, congenital, myopathy for over 50 years and whose skeletal muscle biopsy contains fingerprint bodies; structures resembling a human fingerprint.

\section{CASE REPORT:}

A 54 year old housewife complained of muscle weakness since birth. Her family history was unreliable as she had been adopted. She did not know of any relatives with neuromuscular disease. Her half-sister is normal. Her two children, a male aged 25 years, and a female aged 26 years, have been examined by B.M.S. and are normal. Three young grandchildren are developing normally. 
Details of her past health were from direct enquiry only, as her adopted parents were dead and early medical records were not available. The patient stated that she had muscle weakness since birth. When she was 6 or 7 years old, she was seen at the Hospital for Sick Children and her parents were told she had progressive muscular distrophy and she would not live past her teens. Prior to the age of 10 years, she was able to get around only by crawling on the floor. She recalled being wheeled to school in a wagon by her sister and being carried into class. By age 10 or 11 years, she could walk around holding onto walls. At age 12 years she was finally able to walk unaided. Despite this, her hands were strong and she was able to play the piano and write normally.

During her teens and early twenties, she carried on quite well, finishing grade ten, doing office work for a few years, and then marrying her husband, bearing children and looking after a household. She became quite obese and she had increasing difficulty with walking. Eventually, she lost $100 \mathrm{lbs}$. resulting in improved locomotion. It was about that time that a physician instituted neostigmine therapy. This seemed to improve her strength and well-being and she remained on that medication for several years until that physician died. In 1969 she was seen by B.M.S. who found her as she is now. The patient's strength improved transiently after intravenous Tensilon (edrophonium chloride) and neostigmine $15 \mathrm{mgm}$ q.i.d. was reinstituted and maintained.

Her complaints at the time of her last evaluation included an awkward gait, difficulty in ascending and descending stairs, frequent falling and inability to stand up again, and difficulty in getting out of a low chair. Her arms tired when she combed or washed her hair, or when she reached up to take something off a shelf. There had never been ptosis, diplopia, or weakness of chewing, swallowing or talking. She felt that her wrists, hands, fingers, ankles and feet were normal in strength. She denied fatigability of muscles, cramps or involuntary movements. There were no sensory symptoms. The patient felt that she had not progressed significantly in the past thirty years, and that recent increasing gait unsteadiness was related to $25-30 \mathrm{lb}$. weight increase.

Physical examination revealed a very pleasant, short, obese woman of average intelligence with thin hands and legs and a round, squat body. No fatigability or myotonia could be demonstrated in any muscle group. The cranial nerves were normal, including ocular movements, facial and jaw muscles, and tongue and palate. Moderate neck flexor weakness was present with moderate to moderately severe weakness and some loss of muscle bulk in the muscles about the shoulder, as well as biceps and triceps. The forearm and intrinsic and extrinsic hand muscles showed only mild to moderate weakness. In the lower limbs, weakness was moderately severe in the hip flexors, extensors and abductors, moderate in the quadriceps, hamstrings and ankle dorsiflexors and mild in ankle plantiflexors. She was unable to arise from a horizontal position while lying flat. Her gait was of the waddling type with an exaggerated lumbar lordosis. Sensation was intact. Deep tendon reflexes were just obtainable in both upper and lower limbs. Plantar reflexes were flexor. The remainder of the physical examination was unremarkable.

Hematological studies (Hb., Hct., WBC, differential smear, platelets, ESR, LE cell prep.) were normal as were the antinuclear factor, blood sugar, BUN, serum proteins, serum electrolytes and VDRL. The SGOT was 15 (normal $5-40 \mu$ ) and the LDH 300 (normal up to 400 ). Three CPKs were 68,68 and 59 (normal being 15-45 units). An electrocardiogram showed nonspecific $\mathrm{T}$-wave changes.

Electromyography was carried out on the left deltoid, left extensor digitorum communis (EDC) and left tibialis anterior (TA) using concentric needle electrodes. On full voluntary effort the deltoid showed a loss of motor units with a low amplitude interference pattern. In the clinically stronger EDC and TA muscles, a more complete pattern was observed with maximum contraction but again it was of low amplitude. In all three muscles the individual motor units were markedly reduced in amplitude and duration with an increase in short polyphasic potentials in the EDC and deltoid. There was no spontaneous activity at rest. These findings were felt to be diagnostic of a myopathy. Motor conduction in the left median nerve was normal. Repetitive stimulation of the left median nerve at the wrist was carried out at $1,3,5,10,15$, and 20 per sec. The initial induced action potential in the left abductor pollicis brevis was $4 \mathrm{mv}$ and there was no falloff in amplitude with repetitive stimulation.

\section{MATERIALS AND METHODS}

Under local anesthesia the right deltoid muscle was exposed. Five portions of muscle were removed maintaining their fascicular orientation. Three of these were $0.5 \times 0.5 \times 1.5 \mathrm{~cm}$ and had an untied loop of 3-0 silk suture through one end to facilitate handling. Two pieces measuring 1 $\mathrm{mm} \times 1 \mathrm{~mm} \times 1 \mathrm{~cm}$ were secured at either end by 5-0 silk ties and then removed. One of the larger pieces was immediately frozen by immersion in isopentane, cooled to $-120^{\circ} \mathrm{C}$ by liquid nitrogen. Subsequently cross sections were cut at $6 \mu$ on the cryostat and these were mounted on cover slips. The following staining procedures were carried out: hematoxylin and eosin (H\&E), modified trichrome, periodic-acid Schiff (PAS) with and without diastase, myophosphorylase, myofibrillar ATP-ase (pH 9.4 and 4.5), NAD and SDH (mitochondrial stains) and acid phosphatase (Bancroft, 1967). Histograms were prepared on sections stained for myofibrillar ATP-ase (Brooke and Engel, 1969).

The remaining two large pieces were air dried for 10 minutes. One was fixed in Bouin's solution and the other in Zenker's solution and subsequently embedded in paraffin. Transverse and longitudinal sections were cut at $5 \mu$ and then stained for H\&E, H\&E/Luxol Fast Blue, Gomori trichrome, and PAS.

The smaller two portions were fixed at constant length, one in $2 \%$ osmium and the other in $2 \%$ osmium and postfixed in $5 \%$ glutaraldehyde. They were then dissected and individual blocks were embedded in epon (plastic). Transverse and longitudinal sections were cut at $1 \frac{1}{2} \mu$ and stained with phenylenediamine for light microscopy evaluation. Ultrathin sections were cut at 500-800A, mounted on grids, and then stained with uranyl acetate and/or a lead hydroxide stain. These were examined using an R.C.A. and a Phillips 200.

\section{Light Microscopy:}

There was severe loss of muscle fibers with fat and fibrous connective tissue replacement. There was great variation in fiber size with many tiny round or angular fibers, often with collections of dark pyknotic nuclei, as well as normal-sized and large round fibers (Figure 1, left). The small fibers were in small groups or 

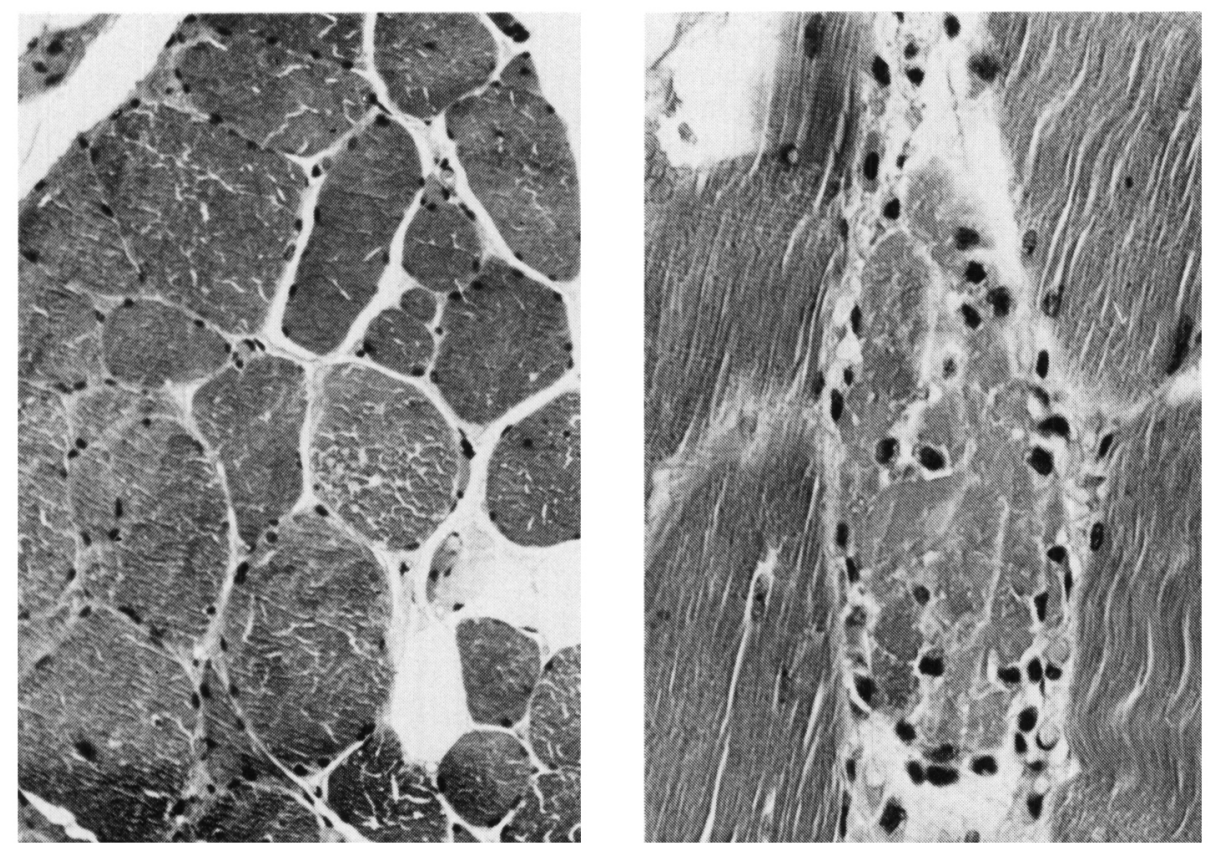

Figure 1. Left: Variation in fiber size with small, normal and large sized fibers; many fibers have internal nuclei. (Mag. 150) Right: Necrotic fiber with loss of cross striations, and internal nuclei. (Mag. 320) H\&E

else scattered amongst the larger fibers. Some fibers had large, pale, vesicular nuclei and others had internal nuclei. Structural changes were numerous, involving small and large fibers. Some fibers exhibited frank necrosis and varying macrophage response (Figure 1, right). Many fibers, especially the smaller ones, contained aggregations of intracellular
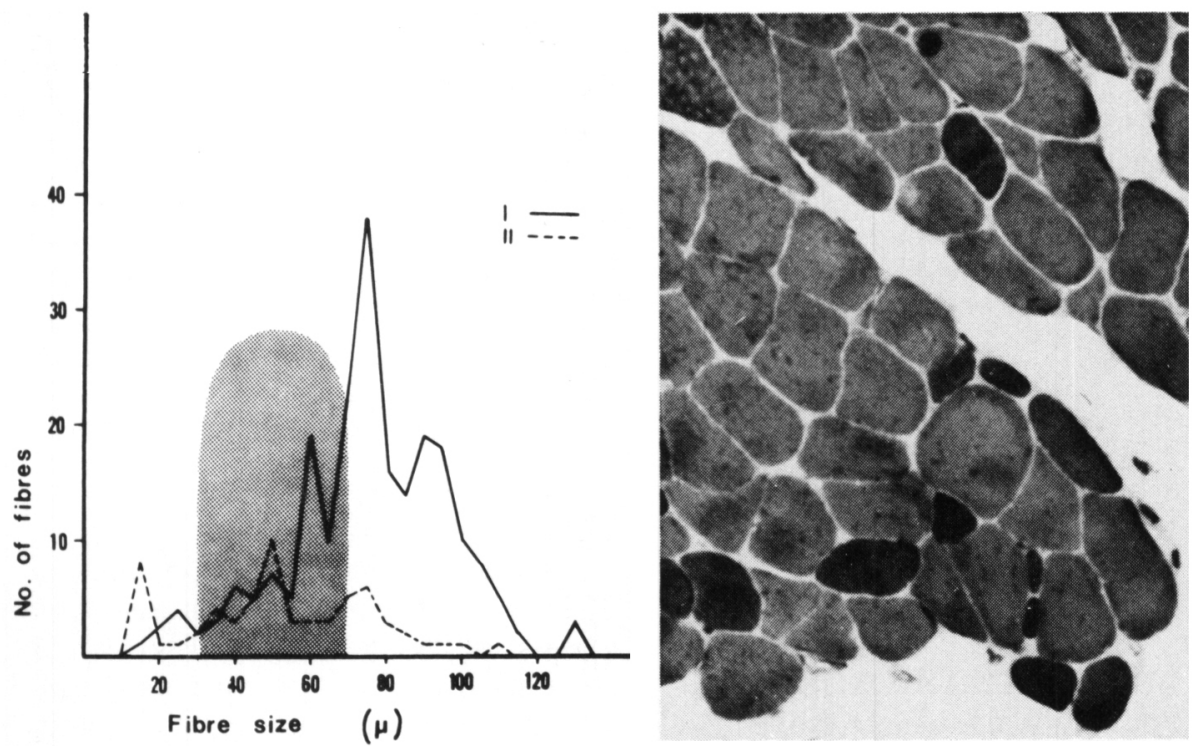

Figure 2. Left: Histogram, with normal range of $30-70 \mu$ shadowed in grey, showing a significant increase in large type I fibers (solid line) and some large type II fibers (dotted lines) as well as small type I and II fibers. Right: Typical field showing type I (light) and type II fibers (dark). (Myofibrillar ATP-ase pH 9.4: Mag. 200) tramuscular arteries and veins were normal.

A histogram on the ATP-ase preparations indicated a $4: 1$ predominance of type I fibers (Figure 2). The type I fibers ranged from 20-130 with a mean diameter of $75-80 \mu$ and a definite shift to the right. The type II fibers ranged from $10-110 \mu$. Atrophy-hypertrophy analysis confirmed an excess of small type I and II fibers, many large type I fibers and a few large type II fibers. There was grouping of type I fibers. Some of the tiny fibers, represented perhaps only by collections of dark pyknotic nuclei, were not included in the analysis as their fiber type could not be determined. Minor, usually subsarcolemmal, areas of focal loss of ATP-ase activity were present in some fibers. Oxidative enzyme preparations (NAD and SDH) revealed subsarcolemmal collections of increased enzyme activity, and paracentral focal enzyme loss with targetoid change. Some fibers contained focal accumulations of acid phosphatase. PAS stain showed collections of PAS positive material some of which remained after diastase treatment, predominantly in a subsarcolemmal location.

\section{Electron Microscopy:}

The striking feature was the presence of numerous fingerprint structures usually seen in fibers undergoing structural change, but also in more normal fibers (Figure 3 and 4). Typically they were discrete, round to ovoid or egg-shaped, but others were irregular, kidney, or cigarshaped. They were usually found subsarcolemmally often lying close to a nucleus. Although they were as large as $5-7 \mu$ in maximum diameter, most were in the $1-2 \mu$ range, while the smallest ones consisted of isolated collections of 1-4 or even 1 circular lamella (Figure 5, left). The fingerprint pattern resulted from a series of lamellae running in all directions throughout the structure, concentrically or in parallel (Figure 4), some at the edge radiating off into the surrounding sarcoplasm. These lamellae were seen to be made up of repeating subunits (Fig. 4 insert). 


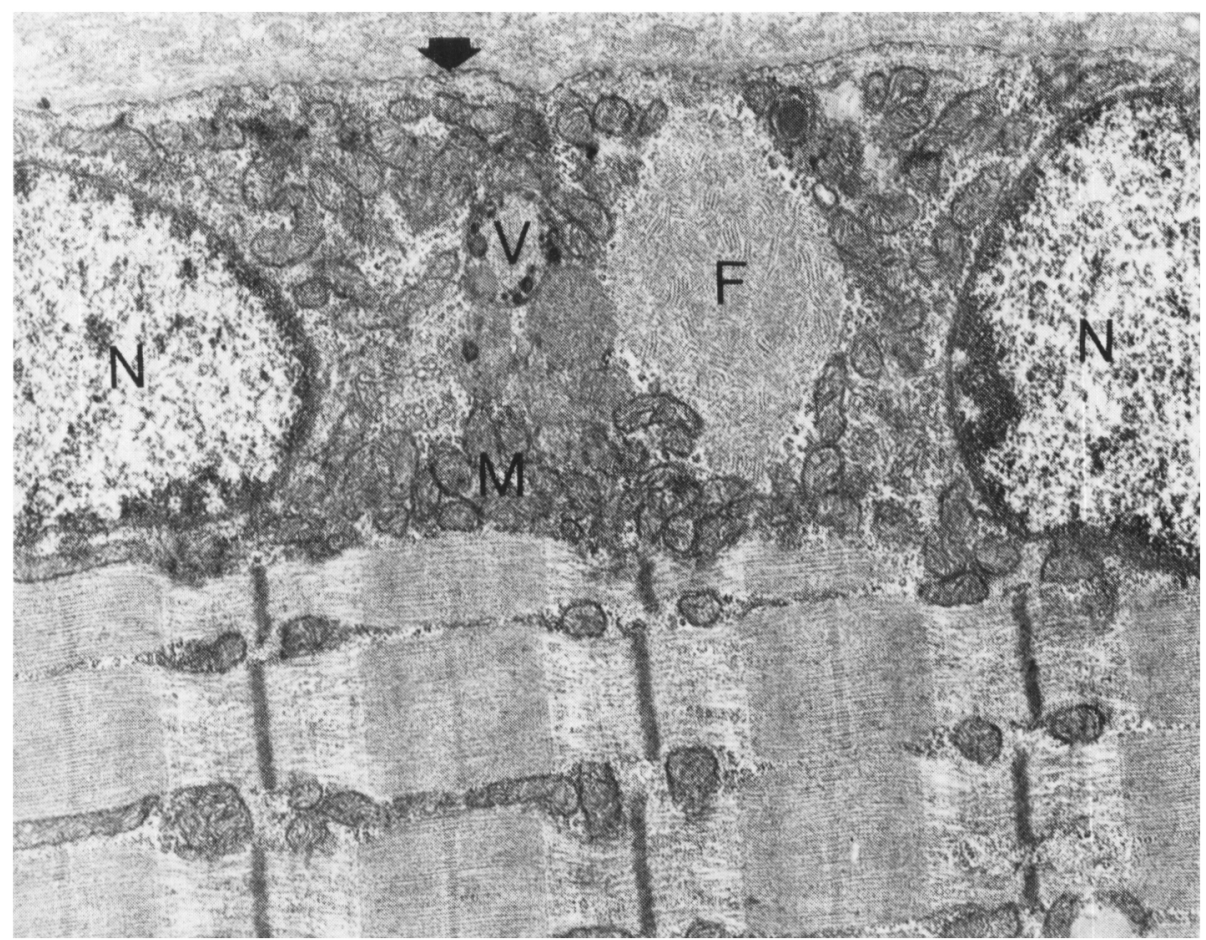

Figure 3. Fingerprint body (F) in type I fiber located beneath sarcoplasmic membrane (arrow) between nuclei (N) and surrounded by mitochondria (M), golgi vesicles and lipid containing vacuoles (V). (Mag. 10,500)

The dimensions of the subunits varied somewhat from fiber to fiber, perhaps in part depending upon the angle of cut and the thick- ness of the sections. They averaged $100 \mathrm{~A}$ in width and $200-300 \mathrm{~A}$ in length. The units usually attained a triangular or trapezoid appearance

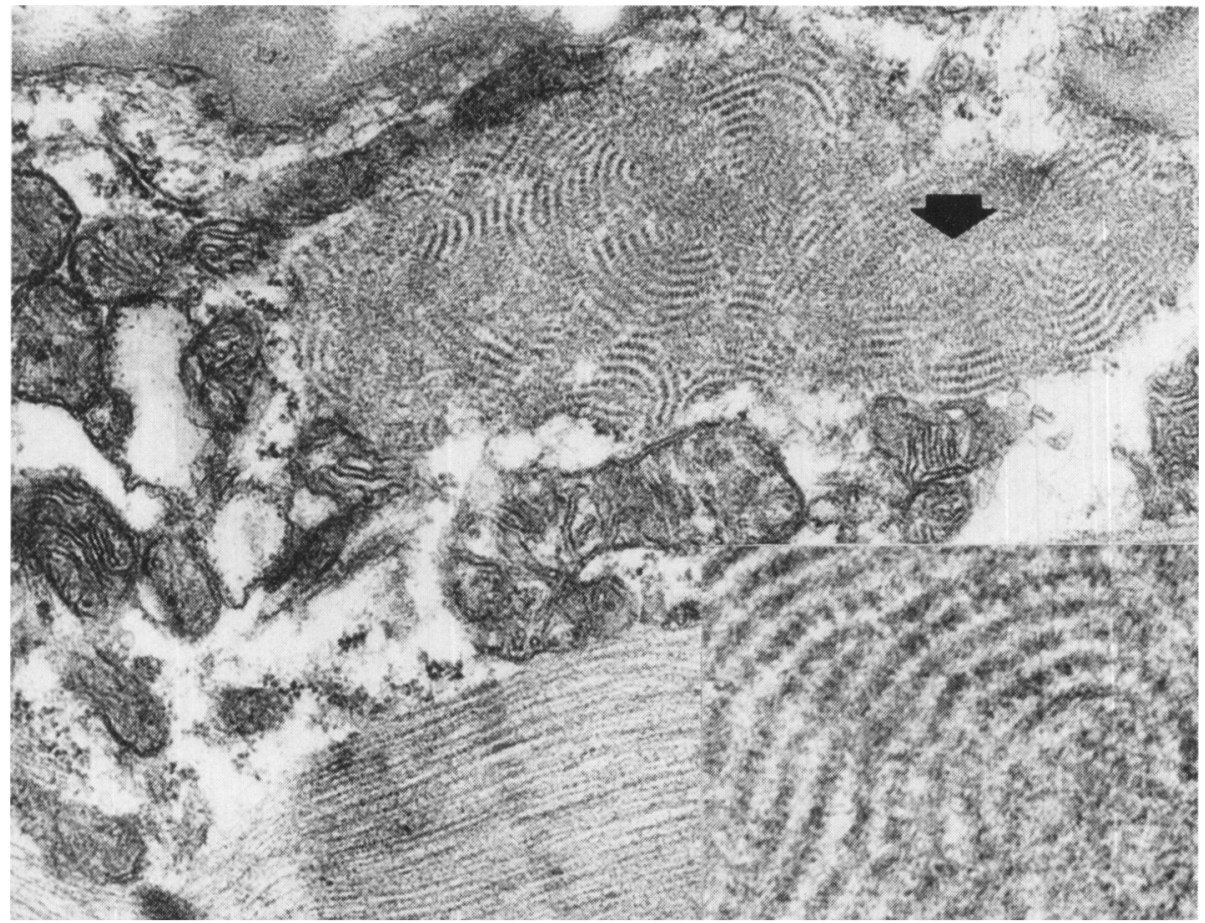

Figure 4. Irregular fingerprint body consisting of a series of lamellae and interposed poorly defined areas (arrow). There is no limiting membrane (Mag. 29,500). Insert shows lamellae are made up of repeating subunits. (Mag. 102,400)
(Figure 5, left). One could trace lamellas for some distance throughout the structure until they either ended or became indistinct. Usually 5 to 15 contiguous lamellae were separated by less well defined areas which might represent in part, tangential sections through the normal lamellar pattern, or disorganized subunits.

One body consisted of 21 parallel rows of lamellae all running into this poorly organized material which had a vague linear pattern (Figure 5, right). The fingerprint pattern was identifiable on transverse sections and had the same configuration. At times, just a few isolated lamellae were seen among an aggregation of mitochondria, autophagic vacuoles or other cellular constituents (Figure 6, upper left). Although the fingerprint bodies were seen near autophagic vacuoles, never were they found within one. Neither were they membrane bound, or were any examples seen with unequivocal filamentous material streaming into their substance.

Many fibers showed structural changes with redundant basement membrane, glycogen accumulation, loss of myofibrillar material, Z-line streaming, mitochondrial aggregates, amorphous material, and excessive lipochrome and neutral fat. Filamentous bodies (Figure 6, lower left), that is collections of $50-60 \mathrm{~A}$ thick filamentous material were present as were autophagic vacuoles either containing complex lipid, cel lular debris, and occasionally myofibrillar material (Figure 6; upper right), or myelin bodies with lamellated lipoprotein (Figure 6, upper left). These structural changes were usually found subsarcolemmally and were often associated with fingerprint bodies and tubular aggregates. One ovoid structure was found which was unidentifiable (Figure 6, bottom right). Its fine structure has some similarity to the dense, less well defined area within the fingerprint bodies, and to that of concentric laminated bodies.

Finally, tubular aggregates were present in great abundance. These were of two distinct varieties. The 

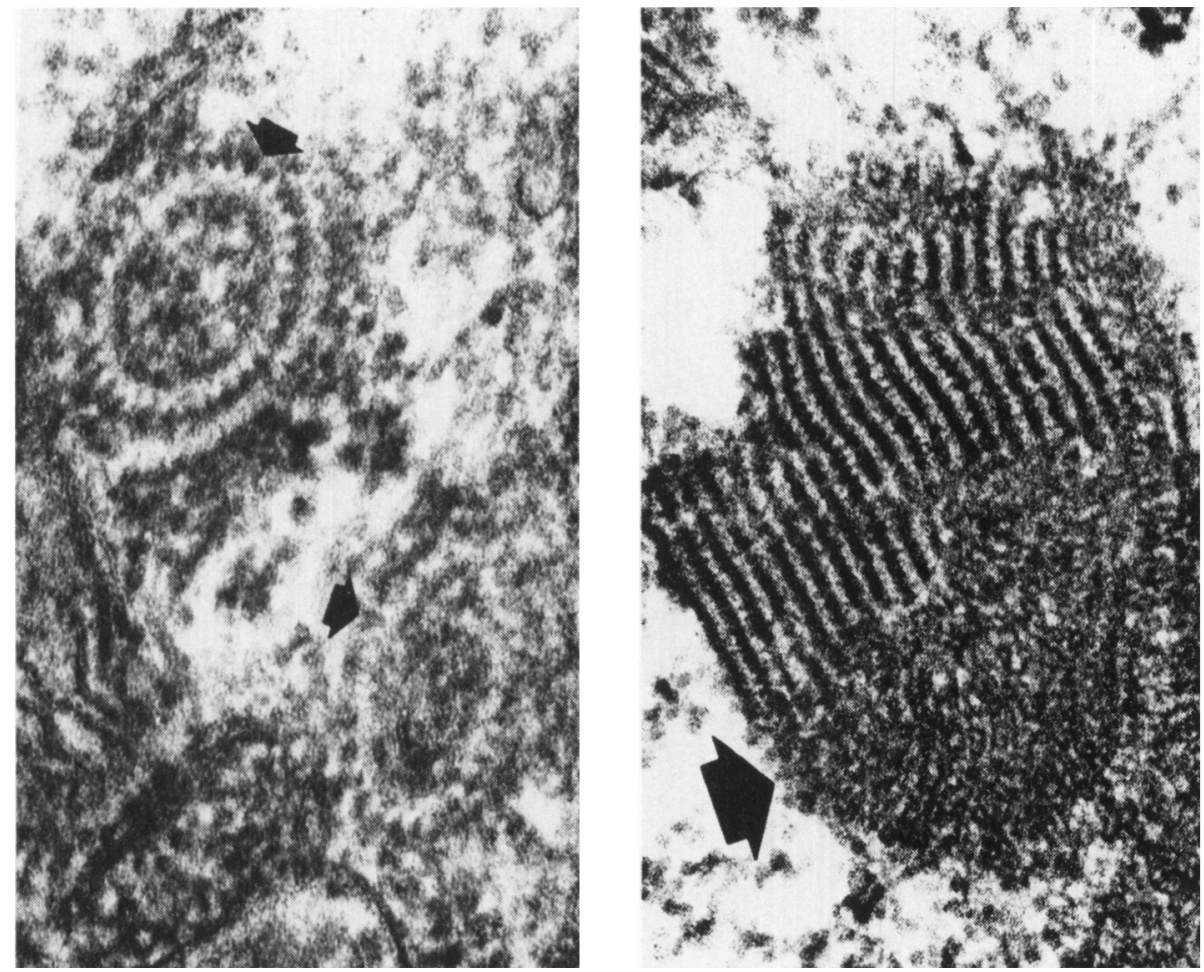

Figure 5. Left: Circular lamellae (arrows) with triangular subunits. (Mag. 130,200) Right: A series of lamellae abruptly changing into a poorly defined area (arrow), suggesting that the lamellae are curving out of the plane of section. (Mag. 87,800)

first were honeycomb bodies (Mair and Tomé, 1972), that is, a collection of tubules some $300 \mathrm{~A}$ in diameter that appear to open into each other diagonally forming a honeycomb pattern. These were loosely packed and not layered and formed bodies up to 3-4 $\mu$ in diameter, and were seen in small atrophic fibers and fibers with considerable structural change. The second type were different and much more prominent (Figure 7) being present in fibers showing structural changes or in more normal fibers. When viewed longitudinally there were usually 5-30 overlapping tubules compactly arranged in parallel layers subsarcolemmally, or less often between sarcomeres, measuring up to $5 \mu$ by $10-15 \mu$ in length. Each tubule was of varying length from 0.5 to $8 u$, with a diameter of $50-75 \mathrm{~m} \mu$. Cross sectional views indicated that the layering was in two planes, with 5-15 tubules per horizontal and vertical row (Figure 7, insert). Each tubule was flush against its neighbor having no inter-connecting bridges. Terminal swellings up to $150 \mathrm{~m} \mu$ in diameter were noted on some of the tubules adjacent to collections of vesicle-like profiles and many of the latter may represent a less orderly array of the dilated tubular components. None of the tubules had a separate inner wall. In many there was amorphous material which was very prominent in some (Figure 8). This material had no definite structure, and was similar to that seen within normal and dilated lateral sacs of the triads.

Using as criteria PAS correlation and $\mathrm{E} / \mathrm{M}$ characteristics (Shafig et al, 1966), (Tice and Engel, 1967) we concluded that fingerprint bodies tended to be in type I fibers whereas tubular aggregates tended to be in type II fibers; however, there were a few examples of tubules and fingerprint bodies in the same fiber.

\section{DISCUSSION}

This patient's illness falls into the benign congenital myopathy group of diseases and she demonstrates that a long survival can occur. She has a myopathic distribution of muscle weakness, a serum CPK that is only slightly elevated, and her history indicates that she has not progressed in
30 years. Her skeletal muscle biopsy has at least one distinguishing morphological feature, the fingerprint body. Although she claimed some improvement with anticholinesterase agents this may have been largely subjective and we do not think she has myasthenia gravis. She does not have bulbar or ocular involvement, displays no fatigability on repeated muscle use, and does not show a myasthenic response with repetitive nerve stimulation.

Microscopy shows evidence of an active myopathy with muscle fiber breakdown and scattered necrotic fibers, as well as evidence of a chronic process with variation in fiber size, internal nuclei, atrophic and hypertrophic fibers, fiber loss and replacement with fat and fibrous connective tissue. Structural changes are plentiful with honeycomb bodies, amorphous material, aggregations of mitochondria and glycogen, targetoid fibres, Z-line streaming, filamentous bodies, lipochrome, neutral fat, numerous polymorphic autophagic vacuoies containing lamellated material, complex lipid and other cellular debris. Many of these abnormalities are byproducts and end-products of destruction of various muscle cell organelles including myofilaments, cell membranes, endoplasmic reticulum and mitochondria. Despite the fact that there is obvious progressive and continuing breakdown of muscle fibers, the patient has not progressed clinically. This may be due to the fact that there has been physiological compensation as evidenced by the hypertrophied fibers.

Tubular aggregates appearing in layers were first described by W. K. Engel who found them in a number of diseases (1970). They contained separate inner walls, were rich in oxidative enzymes and were felt to be confined to type II fibers. Since then, similar tubular aggregates have been described in a number of disorders (Mair and Tomé, 1972), (MorganHughes et al, 1970), (Pearse and Johnson, 1970), (Chui et al, 1973). In many, but not all instances, the tubules contain inner walls which ours do not. Some contain amor- 

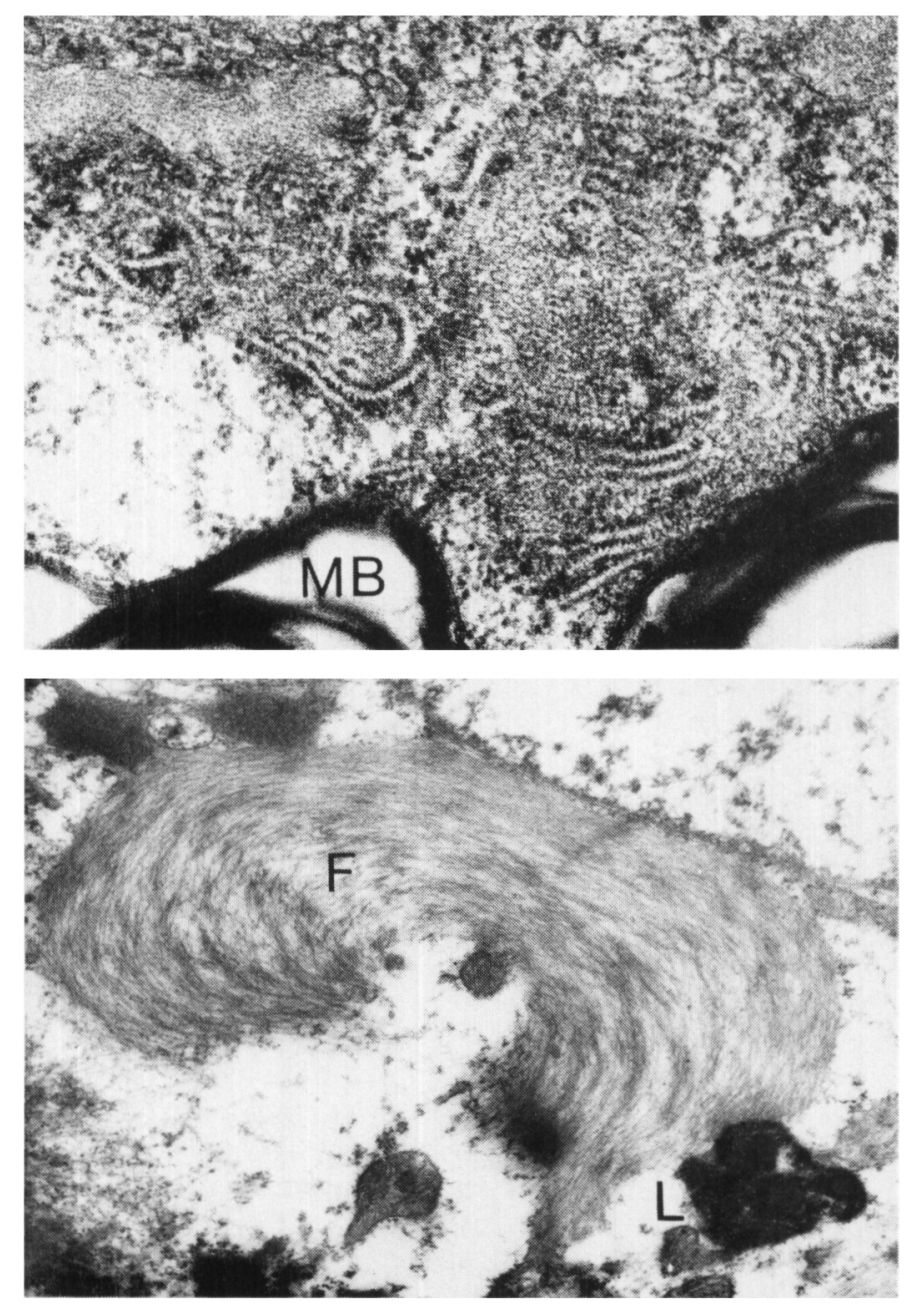

Figure 6. Upper Left: Lamellae of fingerprint material lying next to myelin bodies with lamellated lipoprotein (MB). (Mag. 53,800 )

Bottom Left: Filamentous body (F) with lipochrome (L). (Mag. 48,420)
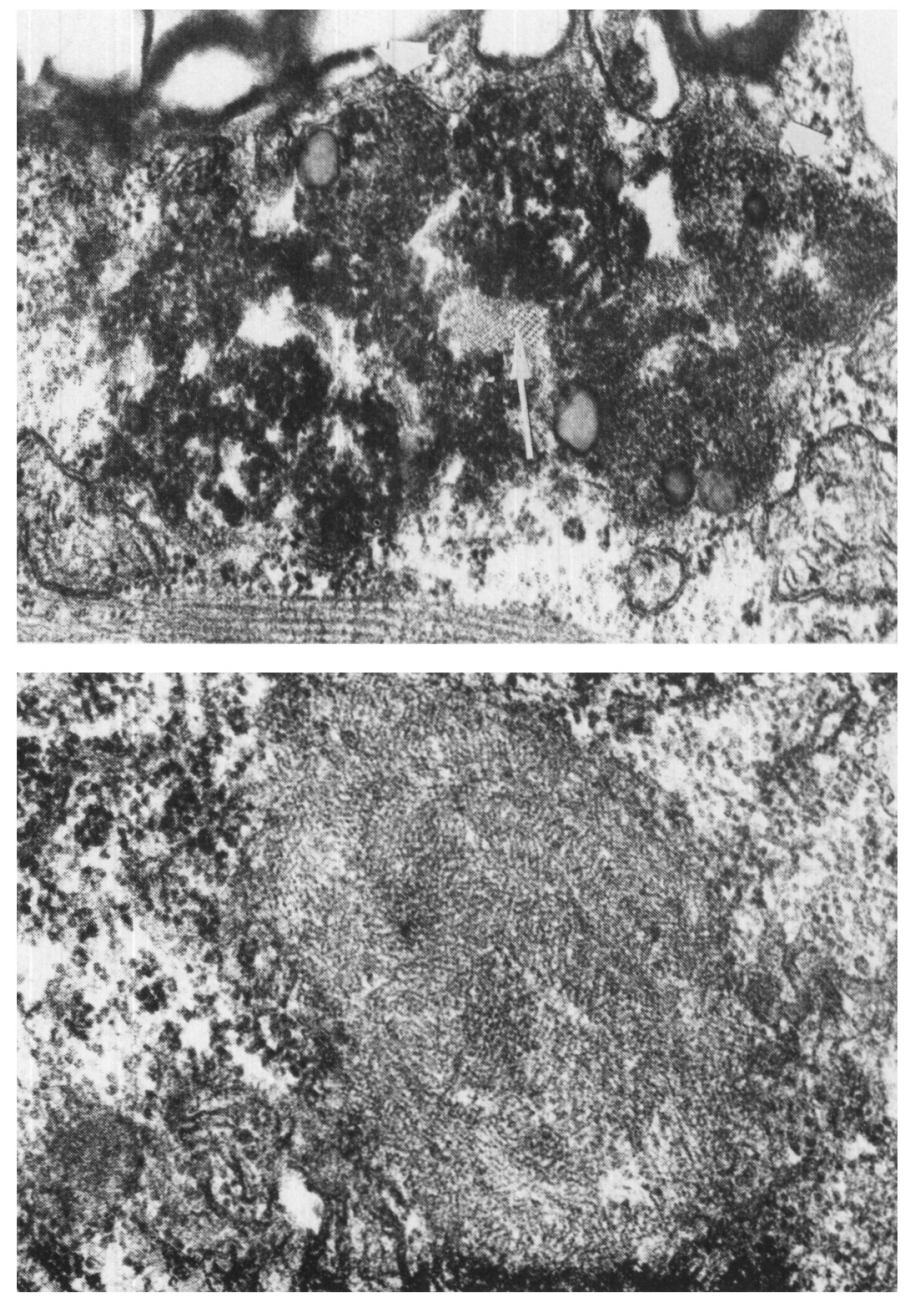

Upper Right: Autophagic vacuoles with limiting membrane (thick arrows) containing dense lipid and A-band material (thin arrow). (Mag. 16,340)

Bottom Right: Round structure without fingerprint pattern but having similarity to dense areas within formed fingerprint bodies. (Mag. 59,200) phous material within them, as did some of ours, and large round intratubular collections of osmophilic material (Figure 8) have been described in a patient with thyrotoxic periodic paralysis (Bergman et al, 1970).

The origin of these tubular aggregates is uncertain. Clusters of 4-5 tubules with dilated ends were found between sarcomeres in areas where the endoplasmic reticulum usually lies and bearing close resemblance to dilated lateral sacs of the triad. The osmophilic material in some tubules (Figure 8) appears identical to that material present in the lateral sacs. For these reason we agree with W. K. Engel that in all likelihood tubular aggregates originate from the endoplasmic reticulum (Engel et al, 1970).

The first reported case of fingerprint body myopathy was that of $\mathrm{A}$. G. Engel and co-workers, who described it in a five year old girl affected since birth. Her muscle showed atrophic and normal size type I fibers and hypertrophic type II fibers. Fingerprint bodies were identified in type I fibers by correlation of light and electron microscopy, but there were no tubular aggregates. Our patient is a 55 year old woman. She has atrophic type I, and more particularly, type II fibers. Her type I fibers tended to be hypertrophic although there were some large type II fibers as well. Numerous structural changes were found representing 50 or more years of muscle cell breakdown. The fingerprint bodies are virtually identical to the ones described by Engel, and are roughly in the same size range, although the repeating subunits are slightly bigger (Engel et al, 1972). We did not see any definite filaments radiating into the fingerprint bodies. No morphological clues indicative of their origin were found, while their composition remains unknown despite the digestive procedures performed by Engel. We believe that the indistinct areas present within the bodies represent to some extent tangential cuts through curving lamellae but may also contain as yet unaligned subunits. No bodies 


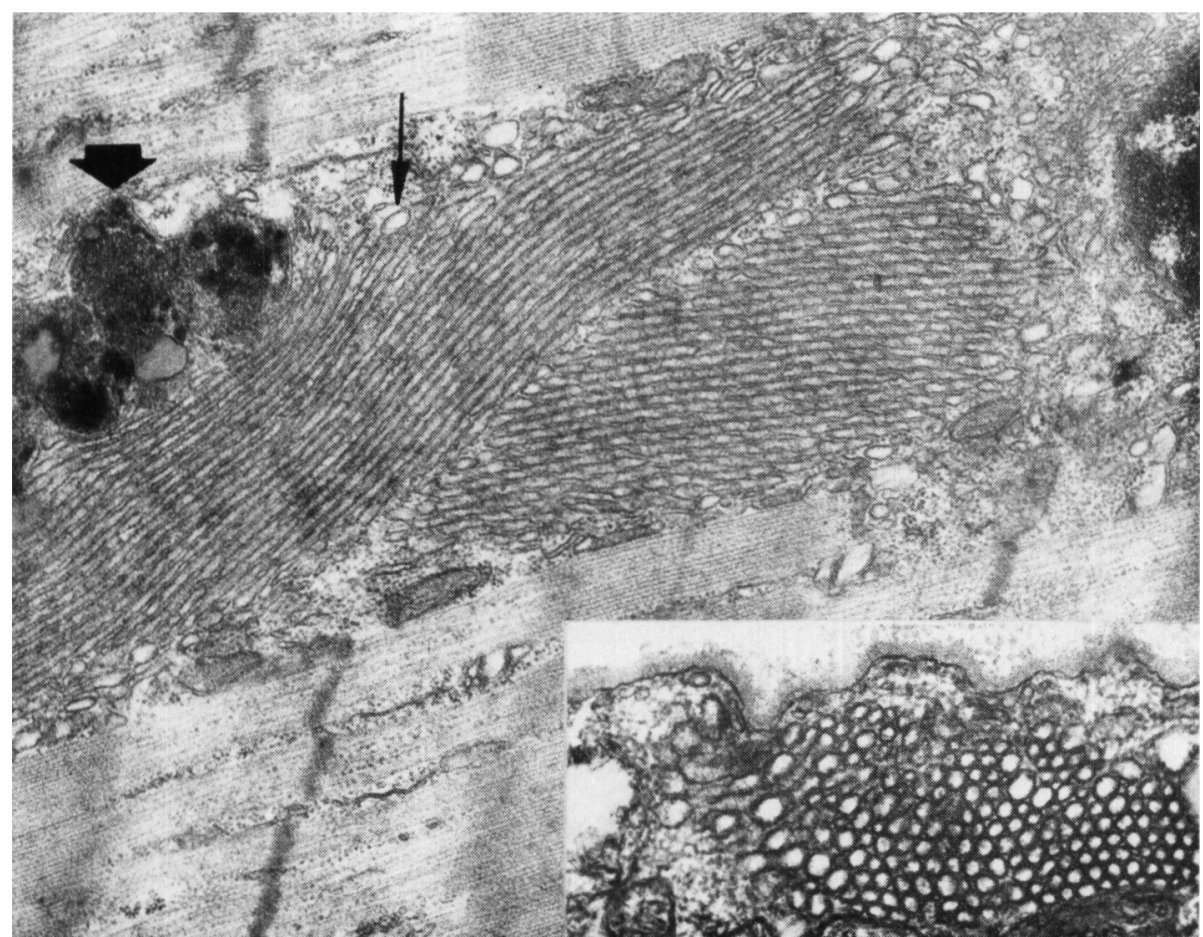

Figure 7. Tubular aggregates consisting of linear tubules and terminal swellings (thin arrow, with adjacent autophagic vacuole (thick arrow). (Mag. 22,680) Insert shows cross-section through tubules demonstrating lack of separate inner tubular wall. (Mag. 26,900)

were seen in what we can appreciate as cross-section, as the lamellae curve in all directions producing a fingerprint pattern in all three planes.

Despite many attempts to do so, no light microscopic correlation of the fingerprint body could be found. Most bodies were in the $1-2 \mu$ range, and at this size they were too small to distinguish from the accompanying cellular debris. There were too many other structures - cytoplasmic bodies, tubular aggregates, filamentous bodies, myelin bodies, mitochondria aggregates, amorphous material, all of which were in the same size range and all tending to. accumulate beneath the sarcoplasmic membrane. For similar reasons we could not identify tubular aggregates with light microscopy. Therefore, specific histochemical analysis of fingerprint bodies and tubular aggregates could not be made. Despite the presence at histochemistry of structures that were variously PAS positive, acid-phosphatase positive, and NAD- and SDH positive, one could not state these were fingerprint bodies, or tubules, or any one of the other distinct abnormalities seen.

As in other benign congenital myopathies this one required the electron microscope for diagnosis. We found no distinguishing morphological feature on routine light microscopy or histochemical studies that would make the diagnosis.

The correlation of EM abnormalities and skeletal fiber types is a trying experience and no one method is entirely satisfactory. In our experience, measurement of Z-line thickness (Engel and Macdonald, 1970) is not of great help and we prefer to assess the fiber type using standard EM characteristics (Shafiq et al, 1966), (Tice and Engel, 1967) and then confirm it by identifying the involved fiber on an adjacent thick section stained with PAS. Using these criteria, fingerprint bodies tended to predominate in type I fibers and tubular aggregates in type II fibers, although both structures were sometimes found in the same fiber.

Although fingerprint bodies were seen adjacent to autophagic vacuoles and other cell breakdown products,

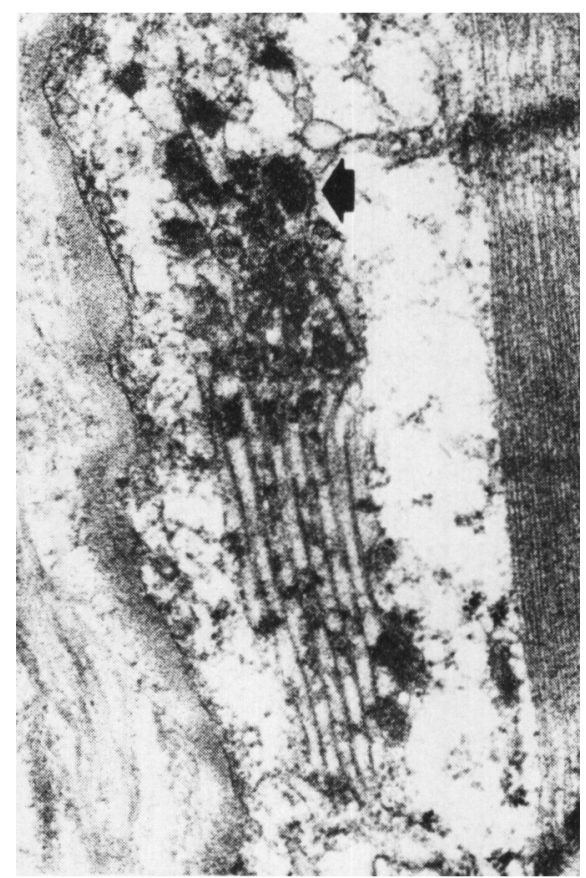

Figure 8. Tubular aggregates containing dense osmophilic material (arrow). (Mag. 26,390)

they are likely of a more specific origin, otherwise they should have been reported much more frequently. Their presence in a case of childhood dermatomyositis. (Carpenter et al, 1972) and in 3 cases of dystrophica myotonica. (Tomé and Fardeau, 1973) led Tomé and Fardeau to suggest that they are not specific for a particular disease. However, neither the case of A. G. Engel or the present one demonstrated evidence of dermatomyositis or dystrophica myotonica. Rather, both of them exhibited features of benign congenital myopathy in which the prominent morphological finding was the fingerprint body. The uniqueness of these bodies in benign congenital myopathy would suggest to us a more specific pathophysiological disorder leading to the formation of the bodies themselves and giving rise to the clinical muscle disorder. While a 4:1 type fiber predominance and type-specific abnormalities might suggest a neurogenic origin, there were no EMG or nerve conduction findings to support this. It is well known that similar abnormal fiber type distributions are seen in other benign congenital myopathies. (Shy et al, 1963), (Shy and Magee, 1956), (Engel et al, 
1971), (Spiro et al, 1966), (Shy et al, 1966), (Engel et al, 1968), (Sher et al, 1967), (Cancilla et al, 1971).

Specific muscle fiber types may be susceptible to exogenous or endogenous factors and the primary lesion could easily be one of muscle. The fingerprint body may represent an end-product or by-product of an enzymatic deficiency in some anabolic or catabolic muscle cell system. This system or defect may be found or expressed predominately in type I fibers. Until the exact nature of their structure and composition has been determined, any discussion of the significance of the fingerprint body must remain speculative.

\section{ACKNOWLEDGEMENTS}

The authors wish to thank Mrs. Maria Kando and Miss Margun Liland for their excellent technical assistance in the preparation of this paper, and Miss Joan Barrett and Miss Susan Shin for typing the manuscript.

\section{REFERENCES}

BANCROFT, J. D. (1967). An Introduction to Histochemical Technique. Butterworth and Company, London.

BERGMAN, R. A., AFIFI, A. K., DUNKLE, L. M., and JOHN, R. J. (1970). Muscle pathology in hypokalemic periodic paralysis with hyperthyroidism. John Hopkins Medical Journal, 126, 100118.

BROOKE, M. H. and ENGEL, W. K. (1969). The histographic analysis of human muscle biopsies with regard to fiber type. I Adult male and female. Neurology (Minneap) 19 , 221-233.

BROOKE, M. H., and NEVILLE, H. E. (1971). Reducing body myopathy. A new disease (Abstract). Neurology (Minneap) 21, 412-413.
CANCILLA, P. A., KALYANARAMAN, K., VERITY, M. A., MUNSAT, T., and PEARSON, C. M. (1971). Familial myopathy with probable lysis of myofibrils in type I fibers. Neurology (Minneap) 21, 579-585.

CARPENTER, S., KARPATI, G., EISEN, A., ANDERMAN, F., and WATERS, G. (1972). Childhood dermatomyositis and familial collagen disease (Abstract). Neurology (Minneap) 22, 425.

CHUI, L., NEUSTEIN, H., MUNSAT, T. L., and HIGGINS, J. (1973). Tubular aggregates in alcoholic myopathy (Abstract) Neurology (Minneap) 23, 433-434.

ENGEL, A. G., ANGELINI, C., and GOMEZ, M. R. (1972). Fingerprint body myopathy, a newly recognized congenital muscle disease. Mayo Clinic Proceedings 47, 377-388.

ENGEL, A. G., GOMEZ, M. R., and GROOVER, R. Y. (1971). Multicore disease. A recently recognized congenital myopathy associated with multifocal degeneration of muscle fibers. Mayo Clinic Proceedings 46, 666-681.

ENGEL, A. G., and MACDONALD, R. A. (1970). Ultrastructural reactions in muscle disease and their light microscopic correlates, in Muscle Disease: Proceedings of an International Congress, Milan, May 1969. pp. 71-89, Editors: Walton, J. N., Canal, N., and Scarlato, G., Excerpta Medica, Amsterdam.

ENGEL, W. K., BISHOP, D. W. and CUNNINGHAM, G. G. (1970). Tubular aggregates in type II muscle Fibers: Ultrastructural and histochemical correlation. Journal of Ultrastructural Research 31, 507-525.

ENGEL, W. K., GOLD, G. N., and KARPATI, G. (1968). Type I fiber hypotrophy and central nuclei. A rare congenital muscle abnormality with a possible experimental model. Archives of Neurology (Chicago) $18,435-444$.

JERUSALEM, F., ENGEL, A. G., and GOMEZ, M. R. (1973). Sarcotubular myopathy: a newly recognized benign congenital familial muscle disease (Abstract), Neurology (Minneap) 23, 408.
MAIR, W. G. P., and TOMÉ, F. M. S. (1972). Atlas of the Ultrastructure of Diseased Human Muscle. Churchill Livingstone, Edinburgh and London.

MORGAN-HUGHES, J.A., MAIR, W. G. P., and LASCELLES, P. T. (1970). A disorder of skeletal muscle associated with tubular aggregates. Brain 93, 873-880.

PEARSE, A. G. E., and JOHNSON, M. (1970). Histochemistry in the study of normal disease with special reference to myopathy with tubular aggregates, in $\mathrm{Mus}$ cle Disease: Proceedings of an International Congress, Milan, May 1969, pp. 25-32. Editors: Walton, J. N., Canal, N. and Scarlato, G., Excerpta Medica, Amsterdam.

SHAFIQ, S. A., GORYCKI, M. A., GOLDSTONE, L., and MILHORAT, A. T. (1966). Fine structure of fiber types in normal human muscle. Anatomical Record $156,283-301$.

SHER, J. H., RIMALOVSKI, A. B., ATHANASSIADES, T. J. and ARONSON, S. M. (1967). Familial centronuclear myopathy: a clinical and pathological study. Neurology (Minneap) 17, 727-742.

SHY, G. M., ENGEL, W. K., SOMERS, J. E., and WANKO, T. (1963). Nemaline myopathy: a new congenital myopathy. Brain 86, 793-810.

SHY, G. M., GONATAS, N. K., and PEREZ, M. (1966). Two childhood myopathies with abnormal mitochondria. I. Megaconial myopathy. II. Pleoconial myopathy. Brain 89, 133-158.

SHY, G. M. and MAGEE, K. R. (1956). A new congenital non-progressive myopathy. Brain 79, 610-621.

SPIRO, A. J., SHY, G. M., and GONATAS, N. K. (1966). Myotubular myopathy. Persistence of fetal muscle in an adolecent boy. Archive of Neurology (Chicago) 14, 1-14.

TICE, L. W. and ENGEL, A. G. (1967). The effect of glucocorticoids on red and white muscles in the rat. American Journal of Pathology 50, 311-334.

TOMÉ, F. M. S. and FARDEAU, M. (1973). "Fingerprint inclusions" in muscle fibers in dystrophia myotonica. Acta Neuropathologica.(Berlin) 24, 62-67. 